\title{
Evaluation of the Effects and the Programming of 'Water Conservation Plan' (WCP) for Total Water Resources Management in Tokyo
}

\author{
Abdul Rahiman NAFISAH*, Jun MATSUSHITA**, Akihiro OKADA** \\ *Faculty of Built Environment, University Technology of Malaysia,UTM Skudai, 51310 Johor, Malaysia. \\ **Division of Regional Environment System, Graduate School of Engineering, Shibaura Institute \\ of Technology, Fukasaku, Minuma-ku, Saitama-shi 335-8857, Japan.
}

\begin{abstract}
In major cities, rapid urbanization due to population and economic growth generally cause increase in water demand. Furthermore, lifestyle change encourages per capita water consumption to increase. The government tends to have policies that support increasing capacity to response to rising demand but this requires huge funding and several other problems such as opposition by environmentalist. To overcome these problems, water demand should decrease especially by reducing per capita water consumption through water conservation. On such basis, this paper focuses on the evaluation of 'Water Conservation Plan' (WCP) implemented by Tokyo Metropolitan Government (TMG). Tokyo faced tight water resources problem during the high economic growth period around 1960s. However, by incorporating both supply and demand side control measures in WCP, Tokyo became advanced in water resources management and now has excess water supply to meet the demands. Tokyo managed to reduce the per capita water consumption to about $171 \mathrm{~L} / \mathrm{p} / \mathrm{d}$ or more in 30 years. But due to pushing-up factors, which contributed $89.5 \mathrm{~L} / \mathrm{p} / \mathrm{d}$ of increment, the actual reduction was equivalent to $81 \mathrm{~L} / \mathrm{p} / \mathrm{d}$ or $19 \%$ reduction rate. Total supply side measures are almost equal to demand side measures where the weightage is 44:56 respectively. Hence, the authors analyze the effects of WCP from the viewpoint of supply and demand side control.
\end{abstract}

Keywords: demand side control, supply side control, total water resources management (TWRM), water conservation plan (WCP)

\section{INTRODUCTION}

\section{Background and Objectives of the Study}

According to the United Nations, many less-developed countries are facing severe water shortage problem, especially the lack of access to clean drinking water. The Millennium Development Goal's (MDG) target for the countries is to fulfill such needs. However, Japan International Cooperation Agency (JICA) reported that medium developed countries such as Asian countries face a different situation in terms of the adequacy of water supply. The main problem leading to water shortage is due to population growth as a result of urbanization and economic growth. In Asia, urban population growth was $6 \%$ per year up to 2005 . Particularly, the population pressure in the city with more than 500,000 people became intensified (Masuda, 2009). Population growth coupled with change of lifestyle directly causes increase in water demand.

Basing on the necessity to establish workable national action programmes for water conservation especially for Asian countries, relevant best practices from other regions in the world could be a reference. In identifying such best practice, the authors realize that Tokyo's Water Conservation Plan (WCP) with necessary modification to local socio-economic condition might be workable for other Asian countries. Tokyo's WCP is

Address correspondence to Abdul Rahiman Nafisah, Graduate School of Engineering, Shibaura Institute of Technology, Email: nafisah.rahiman@gmail.com Received November 19, 2010, Accepted March 17, 2011. 
identified as the best practice since it is reported by the Tokyo Metropolitan Government (TMG) that in a 30 year period, Tokyo managed to reduce the per capita water consumption up to $81 \mathrm{~L} / \mathrm{p} / \mathrm{d}$, approximately $19 \%$ from water supply amount by the WCP. There are no other regions in the world which explicitly declared a successful water consumption reduction due to best practices by their water conservation programmes especially in the wake of rapid urbanization, economic and population growth. Other developing countries could adopt the Tokyo's WCP to establish efficient water conservation programmes. However, without analyzing in detail how Tokyo manages to establish the programme, it is difficult to consider the applicability. Therefore, this study aims to analyze WCP as practiced in Tokyo since TMG did not analyze the effects by the introduction of such WCP in detail for each element.

\section{Review of Related Studies}

Abderrahman (2000) studied the water demand management in Saudi Arabia, while Mayer et al. (1999) and White (2000) both studied on water demand management in Colorado, USA and in Sydney, Australia, respectively. However, all such studies focus on the qualitative study rather than the quantitative study and the elements studied for water conservation are limited to demand side measures. In contrast, this paper focuses on the quantitative study comprehensively from both supply/demand side control measures. White and Fane (2002) however have prepared a comprehensive quantitative study almost similar to this study but the results are mostly from simulation basis. This paper conversely presented results based on the actual data gathered by various approaches. Whereas, Fenwick (1998), Karpiscak et al. (1994) and DeCook et al. (1988) seem to have presented actual quantitative results for water conservation based on case studies in Essex (United Kingdom), Britain and Tucson (Arizona), respectively. However, the case study has limited application, just focusing on area basis or small development basis. On the other hand, this paper focuses on the overall Tokyo Metropolitan region.

The reduction of per capita water consumption in Tokyo is likely due to the effects of the introduction of several measures. In case of researches presented by Tokyo Metropolitan scholars, previous studies mostly examined such effects specifically and independently. For example, Murase et al. (2005) analyzed the relationship between the water price and domestic water demand structure; Yamada et al. (2004) analyzed the domestic water demands according to the size of households; and Nakagawa et al. (2010) analyzed the decreasing tendency of domestic water use per capita by modeling the introduction of water-saving appliances. Nevertheless, effects on domestic water consumption reduction in Tokyo by other measures as leakage reduction, wastewater recycling and rainwater harvesting were not fully examined in the previous studies.

There was a study conducted by Fujii (2002) namely evaluation on water conservation activities in Fukuoka-Shi, which is quite similar and serves as the basis for this study. Nevertheless, Fukuoka's local conditions on water resources are different compared to Tokyo since Fukuoka has restricted water resources availability while Tokyo relatively has abundant water resources. Thus, the consideration on WCP implementation in both regions varies greatly. This paper aims to integrate and analyze WCP from two viewpoints namely supply/demand side control in the basis of chronological and quantitative analysis on the total water resources management (TWRM). 


\section{METHODOLOGY}

The methodology framework of the study is shown in Fig. 1. Mainly, this study is based on empirical analysis performed after collecting relevant data by literature reviews, interviews and field surveys.

\section{OVERVIEW OF THE TOTAL WATER RESOURCES MANAGEMENT IN TOKYO}

Tokyo, with a land area of $2,188 \mathrm{~km}^{2}$, has a population of over 12.5 million. The average annual rainfall is approximately 1,600 $\mathrm{mm}$. High-water consumption style prevails during high economic growth period around 1960s. The completion of Ogouchi Dam in 1957 serves as the final intra-state water resources development within Tokyo. Immediately, Tokyo was hit by strict water shortage due to rapid urbanization and population growth. To deal with the expected water shortages, the government starts the development of inter-state water transfers from Sagami River in 1955 and shortly after from Tone River in 1965. In addition, to cope with continuous water shortages, TMG announced Water Conservation Plan (WCP) in 1973 which consists of supply/demand side control meant for reducing per capita water consumption. Thus, today TMG secures $530 \mathrm{~L} / \mathrm{p} / \mathrm{d}$ of water resources. Out of the total water resources amount, about $80 \%$ is from inter-state water transfers.

\section{Background of 'Water Conservation Plan' (WCP) in Tokyo}

Tokyo needs WCP for several reasons. One of the reasons is due to the tendency towards a substantial growth in the number of people commuting into Tokyo over the periods. Such tendency can be understood by comparing the inflow and outflow movement of the population in Tokyo between the year 1980 and 2005 as shown in Fig. 2(a). It is obvious that daytime population in Tokyo is much higher than nighttime population. Based on the estimated calculation, in 1980, daytime population was $15 \%$

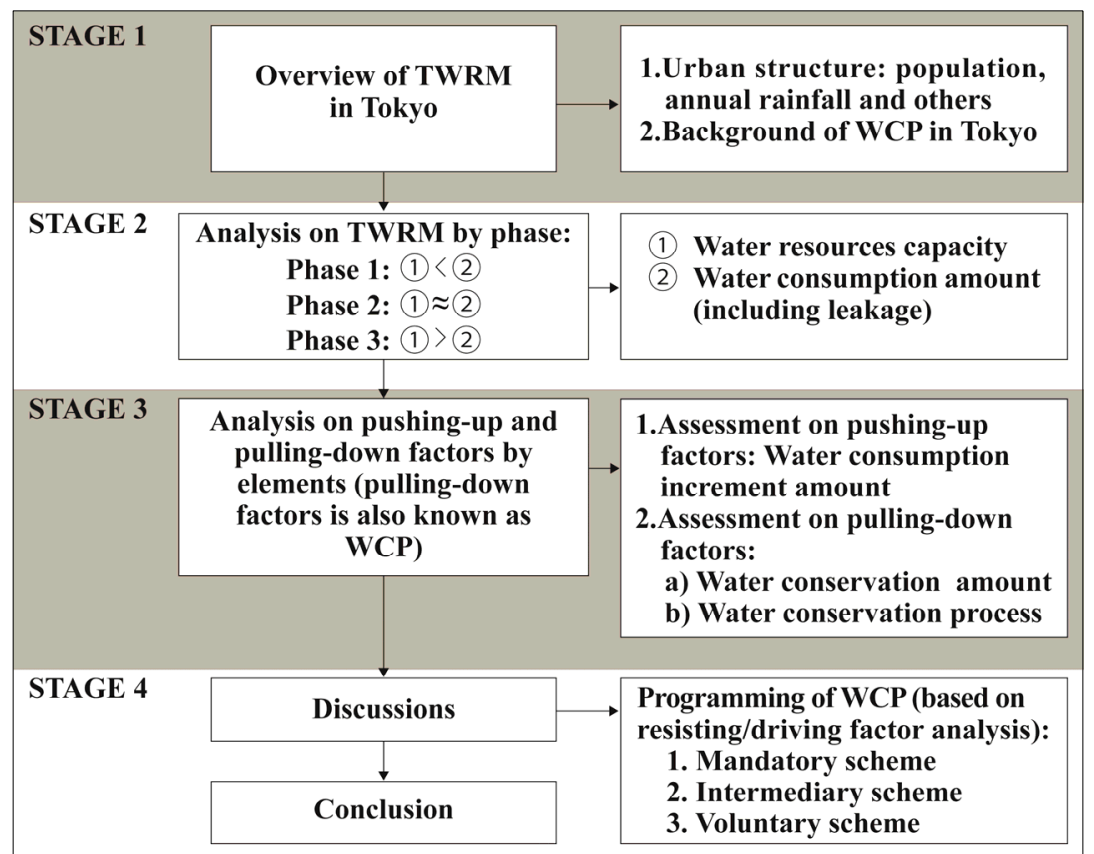

Fig. 1 - Methodology framework 
higher compared to nighttime population while in 2005 , the difference was around $20 \%$. Daytime population against nighttime population growth tendency in 25 years from 1980 to 2005 shows $5 \%$ growth. As such tendency is still continuous; TMG will have to secure more water resources to meet the growing demand.

The local government, TMG realizes that WCP is necessary to be ongoing to limit the capacity development. Another reason is due to the tendency of increasing water demand, where new demand occurs consequent to the increasing number of nuclear families and single families (Saito, 2003). Accordingly, as shown in Fig. 2(b), per capita water consumption increases in a household due to decreasing family members per household. The main reason for such occurrence is assumably due to the custom in Japanese families where they share bath water. Furthermore, as members per household decreases, water consumption increases for washing, bathing and others. Besides, WCP became necessary in Tokyo influenced by the intention of TMG to create a Water Conservation City aiming to promote reasonable water use with resistance to drought and by appreciating limited water resources (Bureau of Waterworks, TMG, 2009).

\section{ANALYSIS ON TWRM IN TOKYO BY PHASE}

In this study, chronologies in TWRM from 1957 to 2007 are to be divided into the following 3 phases: [Phase 1] Period of Increasing Water Consumption (1957 to 1972), [Phase 2] Period of Stabilizing Water Consumption (1973 to 1992) and [Phase 3] Period of Decreasing Water Consumption (1993 to 2007). Likely, such water consumption was influenced by both pushing-up factors and pulling-down factors. Pushing-up factors are due to the change in domestic urban migration structure and the change in family structure with lifestyle combined. While pulling-down factors are materialized through the introduction of supply and demand side control measures under TWRM known as WCP. The basic dimension profile of Tokyo for each phase is shown in Table 1.

\section{Phase 1 (1956 to 1972) - Period of Increasing Water consumption}

As illustrated in Table 1, per capita water consumption in this period shows notable

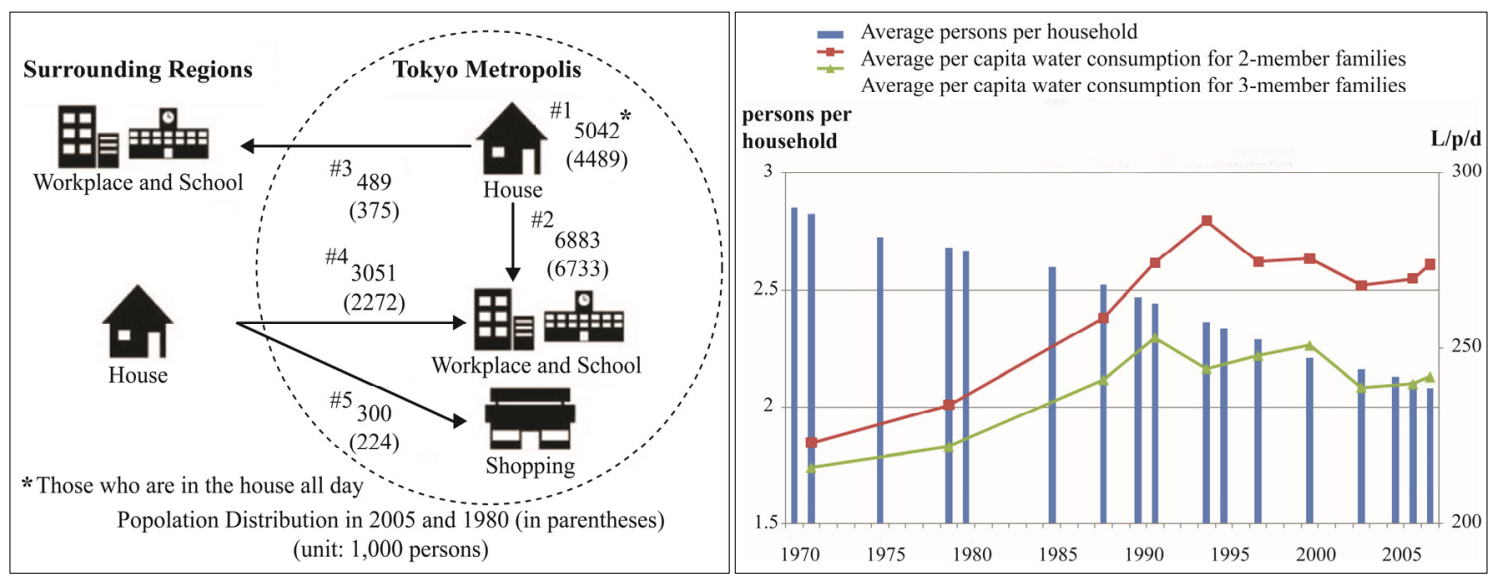

Fig. 2(a) - Tokyo's domestic migration urban structure (Statistics Bureau, Ministry of Internal Affairs and Communication, 1980, 2005)

Fig. 2(b) - Trend of household structure against per capita water consumption (Japan Water Works Association (JWWA), 1997) 
Table 1 - Basic dimension profile of Tokyo by phase (1956-2007)

\begin{tabular}{|c|c|c|c|}
\hline Element & $\begin{array}{c}\text { Phase } 1 \\
\text { Period of Increasing } \\
\text { Water Consumption } \\
1956 \rightarrow 1972 \\
\end{array}$ & $\begin{array}{l}\text { Phase } 2 \\
\text { Period of Stabilizing } \\
\text { Water Consumption } \\
1973 \rightarrow 1992 \\
\end{array}$ & $\begin{array}{c}\underline{\text { Phase } 3} \\
\text { Period of Decreasing } \\
\text { Water Consumption } \\
1993 \rightarrow 2007\end{array}$ \\
\hline General aspects & & & \\
\hline $\begin{array}{l}\text { 1. GRP/year (mil. USD) } \\
\text { 2. Population (mil.) }\end{array}$ & $\begin{array}{r}5.09 \rightarrow 10.9 \\
9.46 \rightarrow 11.16 \\
\end{array}$ & $\begin{aligned} 11.4 & \rightarrow 52.7 \\
11.28 & \rightarrow 11.83\end{aligned}$ & $\begin{aligned} & 57.2 \rightarrow 62.8 \\
& 11.80 \rightarrow 12.75 \\
&\end{aligned}$ \\
\hline Water-related aspects & & & \\
\hline $\begin{array}{l}\text { 1. Water resources } \\
\text { capacity - WR }(\mathrm{L} / \mathrm{p} / \mathrm{d}) \\
\text { 2. Total water supply }\end{array}$ & $264 \rightarrow 408$ & $403 \rightarrow 509$ & $510 \rightarrow 489$ \\
\hline $\begin{array}{l}\text { amount - TWS }(\mathrm{L} / \mathrm{p} / \mathrm{d}) \\
\text { 3. Effective water supply }\end{array}$ & $345 \rightarrow 425$ & $423: 417$ & $413 \rightarrow 347$ \\
\hline $\begin{array}{l}\text { 4. Effective water supply } \\
\text { rate - EWS/TWS }(\%)\end{array}$ & $71 \rightarrow 76$ & $78 \rightarrow 89$ & $89 \rightarrow 97$ \\
\hline $\begin{array}{l}\text { 5. Allowance of water } \\
\text { resources capacity - } \\
\text { WR/TWS (\%) }\end{array}$ & $77 \rightarrow 96$ & $95 \rightarrow 122$ & $124 \rightarrow 141$ \\
\hline
\end{tabular}

\section{Key characteristics of phases:}

Phase 1: Total water supply amount is greater than the water resources capacity resulting in water shortages, although inter-state water transfer was started in 1963. Allowance of water resources capacity (hereinafter defined as allowance) became bigger, but is still in the red.

Phase 2: Total water supply became balanced with the water resources capacity resulting in complete solution to water shortages. Allowance increased more than $120 \%$ which was likely due to both continued interstate water transfers and newly introduced water conservation plan (WCP).

$\underline{\text { Phase 3: }}$ : Total water supply became highly decreased by $66 \mathrm{~L} / \mathrm{p} / \mathrm{d}$ or $15.9 \%$ during this period as a result of successful assimilation by local society to WCP after 20 years of scrutinizing in the preceding phase.

increase from $345 \mathrm{~L} / \mathrm{p} / \mathrm{d}$ in 1956 to $425 \mathrm{~L} / \mathrm{p} / \mathrm{d}$ in 1972, as pushing-up factors are bigger than pulling-down factors. Tokyo was in a high economic growth period in this phase where the economy grew steadily at about $9 \%$ per year, which was from 5.09 thousand USD in 1956 to 10.9 thousand USD in 1972 in Gross Regional Product (GRP). Population growth was rapid; about $18 \%$ of population increment in 16 years bringing significant effects over water supply. In 1954, the total population reached 7.5 million, which is 2.5 times bigger than during World War 2 .

In 1957, the total population reached 8.52 million enabling Tokyo to become the biggest metropolis in the world and in 1962, the total night-time population exceeded 10 million which is the first ever in the world. National policy encourages dam construction and wide-range water supply system or inter-state water transfer to respond to such increasing demand. In 1972, TMG announced the efforts to have sufficient water supply system for the people in Tokyo emphasizing the necessity of water supply development. For counter measures against water shortages, there was water rationing since 1958 to 1973 with maximum water rationing up to $50 \%$ from water supply amount in 1964 to prepare for the $18^{\text {th }}$ Olympic Games held in Tokyo. In 1965, a special committee was established to reduce water leakage. Furthermore, in 1966, the charging system was revised with an average of $35.4 \%$ tariff hike due to the high cost of water resources development. It is obvious that Tokyo faced water shortage where demand for water to support the rapid urbanization and population growth far exceeded the supply capacity. 


\section{Phase 2 (1973 to 1992) - Period of Stabilizing Water consumption}

It is obvious that the per capita water consumption pattern in this period shows fluctuation as shown in Fig. 3, assuming that pushing-up factors became equal to pulling-down factors. Tokyo was in a stabilized economic growth period in this phase where based on GRP, apparently the economic indicator reveal substantial steady growth of roughly 7\% per year, which was from 11.4 thousand USD in 1973 to 52.7 thousand USD in 1992 in GRP. The population growth became stabilized with only 5\% increment in 20 years reducing stress on water supply. In 1980, the population growth became negative for the first time after World War 2.

In this period, although the government continued to develop water resources to meet the ever increasing demand, it also began to give attention on encouraging water conservation. Thus, TMG introduced WCP in 1973 which encouraged water conservation and efficient water usage by various means from supply/demand side control. In 1976, the Ministry of Public Welfare announced the target for the effective water use at $90 \%$. To enhance water supply services, TMG started the promotion of kindness, speed and accuracy among the staff members of Water Bureau in 1983. For public relation, Water Supply Museum was established in 1984 to raise citizens' awareness on water conservation. In 1988, water resources development was integrated into the proposal of the $4^{\text {th }}$ plan for inter-state water transfers from Tone and Ara Rivers.

In the same year, the final report on 'How to Create Water-Saving Type Municipal System' was published. It proposed the necessity of city-wide recycling system and other measures. The fluctuation of water consumption in this period reflects the people's consideration on the WCP introduced. The people are still wondering whether to change their water consumption style according to the mentioned policy or not. Thus, this phase

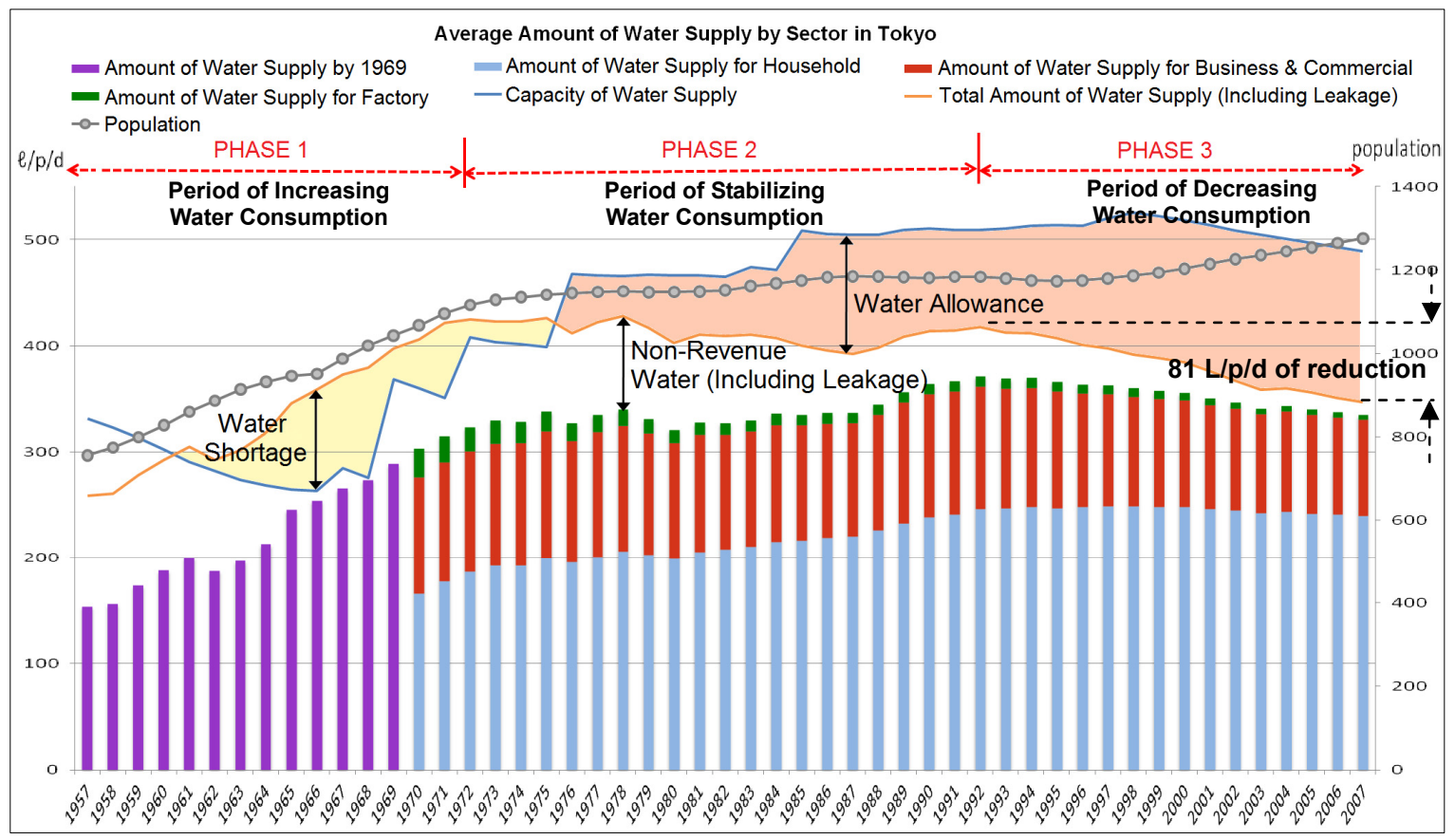

Fig. 3 - Chronological analysis of TWRM in Tokyo by phase (Bureau of Waterworks, Tokyo Metropolitan Government, 1998) 
might be considered as a 'learning phase'. Most probably, due to various measures introduced by the government under such plan, the weightage of pulling-down factors became equal to that of pushing-up factors which stabilized the per capita water consumption. Thus, water consumption stabilization coupled with stabilized population growth increased water allowances capacity more than the water demand.

\section{Phase 3 (1993 to 2007) - Period of Decreasing Water consumption}

The per capita water consumption steadily decreased yearly from $413 \mathrm{~L} / \mathrm{p} / \mathrm{d}$ in 1993 to $347 \mathrm{~L} / \mathrm{p} / \mathrm{d}$ in 2007 while pushing-up factors became smaller than pulling-down factors in this period. Tokyo was in a low economic growth period in this phase when the economy slowed down with a growth rate of only $0.6 \%$ per year, which was decreased from 62.8 thousand USD in 2007 to 57.2 thousand USD in 1993 in GRP. The population growth also remained stabilized with $8 \%$ increment in 15 years. In this period, TMG emphasized the popularization of the consume-less-water urban model with the announcement of a plan toward sustainable water management. In 1996, TMG organized a committee on sustainable water supply system. Consequently, in 1997, the committee produced the final report on 'New Century Plan (STEP 21)' for Tokyo's sustainable water supply. In the same year, Water Science Museum was opened for educational purposes on TWRM. It helped people apprehend that huge water consumption was not appropriate. They started to recognize WCP as a preferable solution toward lower water consumption practice. Due to continuous water resources capacity development coupled with the introduction of WCP in the previous period, the water allowance capacity became higher than water demand. In this period, Tokyo had excess water resources capacity at approximately $150 \mathrm{~L} / \mathrm{p} / \mathrm{d}$ as shown in Fig. 3.

\section{Summary of the Analysis on TWRM by Phase}

Tokyo experienced increasing, stabilizing and decreasing water consumption periods from 1956 to 2007. Changes in population, urbanization, economic condition and government policy have direct impacts on water consumption in each phase as discussed previously. Coincidently, the above-mentioned water consumption periods were the greatest contributors to the economic growth pattern. Besides, during phase 1, water demands are greater than water supply as pushing-up factors are greater than pulling-down factors.

Whereas, in phase 2, water consumption becomes stable as pushing-up factors and pulling-down factors begin to be equalized. In phase 3, water supply continues to be greater than water demand as pulling-down factors become greater than pushing-up factors. However, it is clarified that TMG cannot forecast the future of water consumption change and has no confidence on the successful performance of WCP. Thus, the government tends to increase the water supply capacity corresponding to the water demand during phase 2. As a result, Tokyo currently has excess water supply capacity which enables Tokyo to mitigate water shortage risks in the future.

\section{ANALYSIS ON PUSHING-UP FACTORS AND PULLING-DOWN FACTORS (WCP) IN TWRM BY ELEMENTS}

Table 2 sums up the elements in TWRM based on pushing-up and pulling-down factors of water consumption in Tokyo. Basically, pushing-up factors are attributable to water 
consumption increment, while, pulling-down factors are due to WCP. The subsequent section analyzes the decreasing and increasing amount of per capita water consumption by elements as presented in Table 2 together with the processes involved in its realization. The estimation method is described in Table 3 and Table 4.

\section{Effects on Water Consumption due to Pushing-up Factors ( $\Delta Q 1)$}

There are significant amounts of increment in per capita water consumption due to the change in domestic urban migration structure and the change in family structure combined with lifestyle, despite various efforts by TMG in water consumption reduction as summarized in Table 3 below.

$\Delta \mathbf{Q 1}=$ change in domestic urban migration structure + change in family structure combined with lifestyle

$=22.7 \mathrm{~L} / \mathrm{p} / \mathrm{d}+66.8 \mathrm{~L} / \mathrm{p} / \mathrm{d}$

$=89.5 \mathrm{~L} / \mathrm{p} / \mathrm{d}$

Table 2 - Elements in TWRM based on pushing-up and pulling-down factors

\begin{tabular}{l|c}
\hline \multicolumn{1}{c|}{ Element } & Remarks \\
\hline $\begin{array}{l}\text { Pushing-up factors } \\
\text { - Change in domestic urban migration structure }\end{array}$ & $\Delta \mathbf{Q 1}$ \\
\hline$-\begin{array}{l}\text { Pulling-down factors } \\
\text { 1. Supply side control } \\
\text {-Reduction of non-revenue water: leakage and non-counted water }\end{array}$ & $\Delta \mathbf{Q 2}$ \\
\hline $\begin{array}{l}\text { 2. Direct demand side control } \\
\text {-Save-water type (SWT): flushing toilet and washing machine -Wastewater recycling (WWR) }\end{array}$ & $\Delta \mathbf{Q 3}$ \\
$\quad$-Rainwater harvesting (RWH) -Reduction in industrial sector & \\
\hline $\begin{array}{l}\text { 3. Indirect demand side control } \\
\text {-Water consumption reduction through public relation activities by TMG to raise awareness and to trigger } \\
\text { changes in water use behavior by the introduction of cumulative charging scheme }\end{array}$ & $\Delta \mathbf{Q 4}$ \\
\hline
\end{tabular}

Table 3 - Estimation method for elements under Pushing-up Factors in TWRM

\begin{tabular}{|c|c|}
\hline Estimation Method to Evaluate Water Consumption Pushing-up Factors by Elemen & Amount \\
\hline $\begin{array}{l}\text { Pushing-up factors }(\Delta \mathbf{Q} \mathbf{1}) \\
\text { 1. Change in domestic urban migration structure } \\
\text { - Increment due to population migration structure change from } 1980 \text { to } 2005 \text { with higher population inflow to Tokyo } \\
\text { Metropolis (Population Census } 2005 \text { and } 1980 \text { ) as shown in Fig. } 2(\mathrm{a}) \text { on population movement: } \\
\text {-population inflow in } 1980 / 2005=2.12 / 2.86 \text { (million people). } \therefore 2.86-2.12=0.74 \text { million people increment. } \\
\text { - Increment of } 0.74 \text { million people in } 25 \text { years resulted in increment of total water consumption: } \\
0.74 \text { million people } x 392 \mathrm{~L} / \mathrm{p} / \mathrm{d} \text { (average per capita water consumption from } 1980 \text { to } 2005 \text { ) }=290 \text { million } \mathrm{L} / \mathrm{d} \text {. } \\
\text {-Such total water consumption increment contributes to per capita water consumption increment based on the population } \\
\text { in } 2007(12.752 \text { million people) as follows: } 290 \text { million.L/d } \div 12.752 \text { million people }=22.7 \mathrm{~L} / \mathrm{p} / \mathrm{d}\end{array}$ & $22.7 \mathrm{~L} / \mathrm{p} / \mathrm{d}$ \\
\hline $\begin{array}{l}\text { 2. Change in family structure combined with lifestyle } \\
\text { - Increment in total water consumption due to family structure change combined with lifestyle from } 1979 \text { to } 2007 \text {. } \\
\text { Higher per capita water consumption by household due to declining family members per household together with the } \\
\text { progress of water-consuming lifestyle (Japan Water Works Association (JWWA), 1997): } \\
\text {-per capita water consumption by } 2 \text { family-member households in } 1979 / 2007=234 / 274(\mathrm{~L} / \mathrm{p} / \mathrm{d}) \\
\text {-per capita water consumption by } 3 \text { family-member households in } 1979 / 2007=222 / 242(\mathrm{~L} / \mathrm{p} / \mathrm{d}) \\
\text {-As a result, increment in the total water consumption due to per capita water consumption increment from } 226 \mathrm{~L} / \mathrm{p} / \mathrm{d} \text { in } \\
1979 \text { where the average members of household was } 2.68 \text { people to } 270 \mathrm{~L} / \mathrm{p} / \mathrm{d} \text { in } 2007 \text { where the average members of } \\
\text { household was } 2.12 \text { people is calculated as follows: }\{[270 \mathrm{x} 12.752 \text { (population in } 2007)]-[226-11.465 \text { (population in } \\
\text { 1979) }\}=852 \text { million.L/d. } \\
\text {-Such total water consumption increment contributes to per capita water consumption increment based on the population } \\
\text { in } 2007 \text { (12.752 million people) as follows: } 852 \text { million.L/d } \div 12.752 \text { million people }=66.8 \mathrm{~L} / \mathrm{p} / \mathrm{d}\end{array}$ & $66.8 \mathrm{~L} / \mathrm{p} / \mathrm{d}$ \\
\hline Total $(\Delta \mathbf{Q} 1)$ & $89.5 \mathrm{~L} / \mathrm{p} / \mathrm{d}$ \\
\hline
\end{tabular}




\section{Effects on Water Consumption due to Pulling-down Factors}

Regarding pulling-down factors, there are 3 categories in measuring water conservation effects as follows: supply side control $(\Delta \mathrm{Q} 2)$, direct demand side control $(\Delta \mathrm{Q} 3)$, and indirect demand side control $(\Delta \mathrm{Q} 4)$ as summarized in Table 4 below.

Table 4 - Estimation method for elements under pulling-down factors in TWRM

\begin{tabular}{|c|c|}
\hline Estimation Method to Evaluate Water Consumption Pulling-down Factors by Elements & Amount \\
\hline Pulling-down factors: Supply side control $(\Delta Q 2)$ & \\
\hline Reduction of non-revenue water: leakage and non-counted water & \\
\hline - Decrement due to water conservation through leakage and non-counted water amount reduction from 1978 to 2007 & \\
\hline (interview with Waterworks Bureau of TMG): & \\
\hline - leakage amount in 1978/2007=67/12 (L/p/d) $\therefore 67-12=55 \mathrm{~L} / \mathrm{p} / \mathrm{d}$ & $55 \mathrm{~L} / \mathrm{p} / \mathrm{d}$ \\
\hline - non-counted water amount in $1978 / 2007=21 / 1(\mathrm{~L} / \mathrm{p} / \mathrm{d}) \therefore 21-1=20 \mathrm{~L} / \mathrm{p} / \mathrm{d}$ & $20 \mathrm{~L} / \mathrm{p} / \mathrm{d}$ \\
\hline Total $(\Delta Q 2)$ & $75 \mathrm{~L} / \mathrm{p} / \mathrm{d}$ \\
\hline Pulling-down factors: Direct demand side control $(\Delta \mathbf{Q})$ & \\
\hline 1. Save-water type flushing toilet (SWT-FT) & \\
\hline Water conservation by SWT-FT for a newly-built house case: & \\
\hline [Growth rate of SWT-FT $\times$ number of people using toilet daily $\times$ water conservation amount by SWT-FT] $\div$ Population & \\
\hline $\begin{array}{l}\text { in } 2007 \\
\text { Before analyzing the amount saved by SWT-FT, the following items are defined: }\end{array}$ & \\
\hline $\begin{array}{l}\text { (1) Growth rate of SWT-FT from } 1994 \text { to } 2007 \text { (1t model of SWT-FT was available from 1994) is assumed as } \\
\text { proportionate to housing unit growth rate during the period. Housing units' growth rate }=(6.03-4.53) / 4.53 \text {, about } \\
33.1 \% \text {; where total housing units in } 1994 / 2007=4.53 / 6.03 \text { (unit: million) (Statistics Bureau, Ministry of Internal } \\
\text { Affairs and Communication, 1994, 2007). }\end{array}$ & \\
\hline $\begin{array}{l}\text { (2) Number of people using toilet daily referring to population movement as shown in Fig. } 2 \text { (a) are divided into } 5 \\
\text { categories: }\end{array}$ & \\
\hline $\begin{array}{l}\# 1 \text { and } \# 2 \text { are counted full as the people are in Tokyo all the time, while } \# 3, \# 4 \text { and } \# 5 \text { are counted as half assuming } \\
\text { that people are in Tokyo for half a day: } 6.883+5.042+[(3.051+0.489+0.3) \times 0.5)=13.845 \text { people (unit: million) }\end{array}$ & \\
\hline (3) Water conservation amount by SWT-FT $=(52-21) \mathrm{l} / \mathrm{p} / \mathrm{d}$; where: & \\
\hline i. Toilet usage - 3times (urination) /1time (defecation) (interview with TOTO Co. Ltd.) & \\
\hline ii. Amount of water consumed for each flushing (TOTO Co. Ltd.): & \\
\hline -Flushing toilet model from 1970 to 1993: $13 \mathrm{~L}$ for both urination and defecation. Daily average: $13 \times(3+1)=52$ & \\
\hline $\mathrm{L} / \mathrm{p} / \mathrm{d}$. & \\
\hline -Flushing toilet model of $2007-5 \mathrm{~L}$ for urination and $6 \mathrm{~L}$ for defecation. Daily average: $(3 \times 5)+(1 \times 6)=21 \mathrm{~L} / \mathrm{p} / \mathrm{d}$ & \\
\hline$\therefore 0.331 \times 13.845 \times(52-21)=142.1$ million.L/d & \\
\hline
\end{tabular}

-Such amount contributes to per capita water consumption reduction based on the population in 2007 (12.752 million people) as follows: $142.1 / 12.752=11.1 \mathrm{~L} / \mathrm{p} / \mathrm{d}$

b. Water conservation by SWT-FT for toilet-only renewal case:

- The weightage of SWT-FT stand at 1 for a newly-built house case and approximately 1 for toilet-only renewal case (interview with the Marketing Department of TOTO Co. Ltd.). Hence, the amount of conservation by SWT-FT in toilet-only renewal case $=$ amount of conservation by SWT-FT for a newly-built house case $=11.1 \mathrm{~L} / \mathrm{p} / \mathrm{d}$

$\therefore$ Total amount of water conservation by SWT-FT: $11.1 \mathrm{~L} / \mathrm{p} / \mathrm{d}+11.1 \mathrm{~L} / \mathrm{p} / \mathrm{d}=22.2 \mathrm{~L} / \mathrm{p} / \mathrm{d}$.

2. Save-water type automatic washing machine (SWT-AWM)

Number of washing machines in $2007 \mathrm{x}$ washing machine usage $\mathrm{x}$ water conservation amount by SWT-AWM (compared between 1970 and 2007$) \div$ population in 2007

Before analyzing the amount saved by SWT-AWM, the following items are defined:

(1) Number of washing machines in $2007=6.03$ mil. units (housing units in 2007)

(2) Washing machines usage $=1$ ( 1 unit per household) $x 1$ (usage of 1 time washing/day) (Japan Electric Appliances Association, 2009)

(3) Water conservation amount by SWT-AWM $=\{[(165-110) \times 0.9]+[(165-101) \times 0.1]\}$ where:

i. The replacement of washing machine or the average lifespan of washing machine is 8.7 years. In 2007, washing machines in $90 \%$ of housing units are of 2002-model and only $10 \%$ are of 2007 -model. (Japan Electric Appliances Association, 2009).

ii. Amount of water consumed in each washing:

- 1970-model (traditional double-layer type washing machine) - $165 \mathrm{~L} /$ washing (Bureau of Waterworks, Tokyo Metropolitan Government, 1973).

- 2002-model (SWT-automatic washing machine) - $110 \mathrm{~L} /$ washing (amount obtained by interpolation method between 1970 and 2007)

- 2007-model (SWT-automatic washing machine) - $101 \mathrm{~L} /$ washing (average amount obtained by comparing several washing machine models by several makers) 
-Such amount contributes to per capita water consumption reduction based on the population in 2007 (12.752 million people) as follows: $337 / 12.752=26.4 \mathrm{~L} / \mathrm{p} / \mathrm{d}$

3. Wastewater recycling (WWR)

- Total in-house WWR amount in 2007 (interview with City Planning Department of TMG): 85.4 million.L/d

-Such amount contributes to per capita water consumption reduction based on the population in 2007 (12.752 million people) as follows: $85.4 / 12.752=6.7 \mathrm{~L} / \mathrm{p} / \mathrm{d}$

4. Rainwater harvesting (RWH)

- Total RWH amount in Sumida-ku in 2007 (interview with Sumida-ku City Hall):

12.7 million.L/d x 10 times/year $\div 365=0.35$ million $\mathrm{L} / \mathrm{d}$

- Such amount contributes to per capita water consumption reduction based on the population in 2007 (12.752 million people) as follows: $0.35 / 12.752=0.03 \mathrm{~L} / \mathrm{p} / \mathrm{d}$

5. Reduction in industrial sector (Bureau of Waterworks, Tokyo Metropolitan Government, 1979, 2007).

- Reduction observed by decrement in industrial water amount from year 1979 to 2007 : -amount of industrial water in 1979/2007 $=160 / 58$ (million.L/d). $\therefore 160-58=102 \mathrm{million} . \mathrm{L} / \mathrm{d}$.

-Such amount contributes to per capita water consumption reduction based on the population in 2007 (12.752 million people) as follows: $102 / 12.752=8 \mathrm{~L} / \mathrm{p} / \mathrm{d}$. Such total reduction in industrial sector is mainly due to:

i. Decrement by factory relocation to the outskirts of Tokyo Metropolis: 15 million.L/d (total water consumed by top 20 ranking factories consuming large amount of water in Tokyo in 1979)

-Such amount contributes to per capita water consumption reduction based on the population in 2007 (12.752 million people) as follows: $15 / 12.752=1.2 \mathrm{~L} / \mathrm{p} / \mathrm{d}$

ii. Decrement by the use of WWR due to higher water cost expected upon the introduction of cumulative water charging scheme in $1975: 8 \mathrm{~L} / \mathrm{p} / \mathrm{d}-1.2 \mathrm{~L} / \mathrm{p} / \mathrm{d}=6.8 \mathrm{~L} / \mathrm{p} / \mathrm{d}$ (estimated by reverse calculation).

Total ( $\Delta$ Q3)

Pulling-down factors: Indirect demand side control $(\Delta Q 4)$

- Water consumption reduction through public relation activities by TMG to raise awareness and to trigger changes in water use behavior by the introduction of cumulative charging scheme since 1973. Amount saved is estimated by reverse calculation as this element is an intangible measure: $[81-(63.3+75-89.5)] \mathrm{L} / \mathrm{p} / \mathrm{d}$
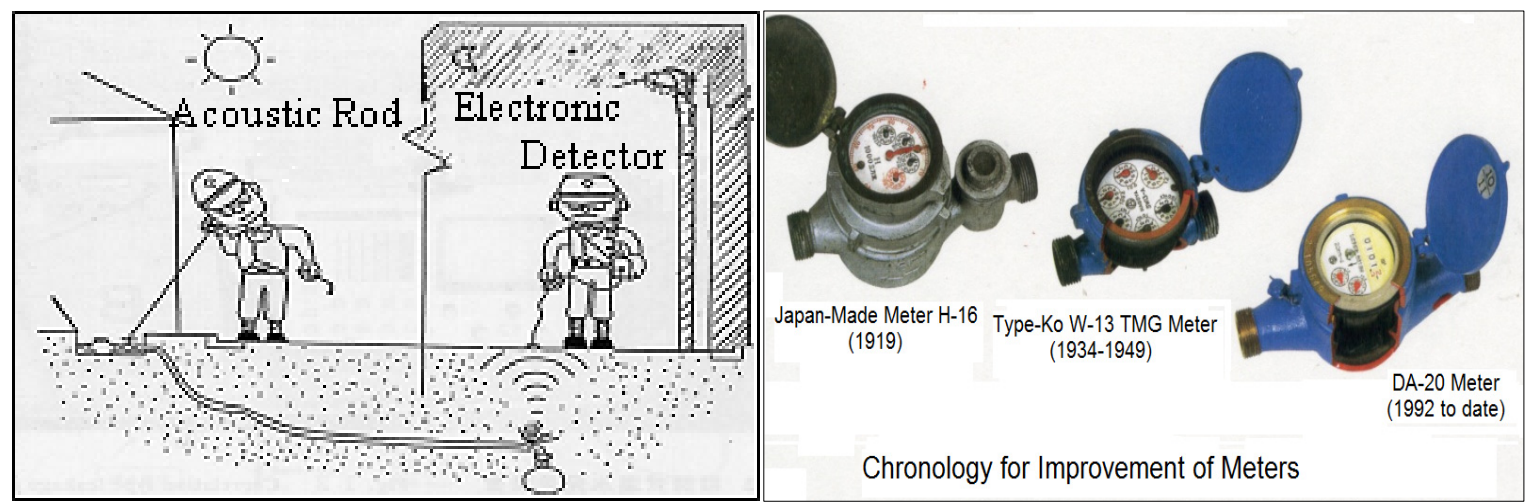

Fig. 4 - Non-revenue water reduction activities by TMG (Bureau of Waterworks, Tokyo Metropolitan Government, 1998)

\section{Water Conservation Effects by Supply Side Control $(\Delta Q 2)$}

Supply side control measures by TMG consist of leakage reduction and other non-counted water reduction.

$\Delta \mathbf{Q 2}=$ leakage reduction + other non-counted water reduction

$$
=55 \mathrm{~L} / \mathrm{p} / \mathrm{d}+20 \mathrm{~L} / \mathrm{p} / \mathrm{d}
$$

$$
=75 \mathrm{~L} / \mathrm{p} / \mathrm{d}
$$


Huge amounts of water are conserved over the past 50 years (in 1956 the leakage rate was $20 \%$ while in 2007 the leakage rate was reduced to $3.3 \%$ ). Mainly, the following four measures were taken to realize water consumption reduction by leakage and other non-effective water reduction: pressure reduction in pipe, replacement of fragile piping material (cast iron to ductile/stainless steel pipe), technical development such as acoustic sound detector and instant repair method corresponding to users' complaints.

\section{Water Conservation Effects by Direct Demand Side Control ( $\Delta Q 3)$}

Direct demand side control measures consist of the development of save-water type (SWT) devices, i.e. SWT flushing-toilets and automatic washing machines; wastewater recycling (WWR); rainwater harvesting $(\mathrm{RWH})$; and reduction in industrial sector.

$\Delta \mathbf{Q 3}=$ SWT-flushing toilet + SWT washing machine + WWR + RWH + reduction in industrial sector

$$
\begin{aligned}
& =22.2 \mathrm{~L} / \mathrm{p} / \mathrm{d}+26.4 \mathrm{~L} / \mathrm{p} / \mathrm{d}+6.7 \mathrm{~L} / \mathrm{p} / \mathrm{d}+0.03 \mathrm{~L} / \mathrm{p} / \mathrm{d}+8 \mathrm{~L} / \mathrm{p} / \mathrm{d} \\
& =63.3 \mathrm{~L} / \mathrm{p} / \mathrm{d} \ldots \ldots \ldots \ldots \ldots \ldots \ldots \ldots \ldots \ldots \ldots \ldots \ldots \ldots \ldots \ldots \ldots \ldots \ldots \ldots \ldots \ldots \ldots \ldots \ldots \ldots \ldots \ldots \ldots \ldots \ldots \ldots \ldots
\end{aligned}
$$

The details for each measure are as follows:

\section{Save-water Type Flushing Toilet (SWT-FT)}

In order to introduce SWT-FT, TMG had started its own research before any relevant makers carried out such research. In 1973, TMG requested the Society of Heating, Air-conditioning and Sanitary Engineers of Japan to conduct a technical research on how to save water in flushing excreta particularly on the pipe diameter, slope and correlation between distances of water transfer with less water. Based on the result, TMG requested the makers to manufacture SWT-FT. As the request is assumedly coincident with the makers' business strategy, the development of SWT-flushing toilets continued further to date. The development processes of SWT-FT by TOTO Co. Ltd., one of the leading toilet makers in Japan is shown in Fig. 5(a).

\section{Save-Water Type Automatic Washing Machine (SWT-AWM)}

Water used for laundry $(16 \%)$ has among the biggest percentage of water consumption in domestic water use (Ministry of Land, Infrastructure, Transport and Tourism (MLIT), 2003). In 1973, TMG requested Japan Quality Association (JQA) formerly known as Foundations of Machine and Electronics Inspection Association to conduct a research on the amount of water consumed during the operation of washing machines by comparing several options on washing methods. As a result, dewatering before rinsing was the most appropriate as the remaining detergent concentration reduced sharply and the continuation of dewatering could be shortened. Consequently, TMG requested the manufacturer to improve the SWT-AWM.

Within a year, the manufacturers produced the initial automatic washing machine models. Once again TMG carried out experiments on models from those makers. The results showed that system programming was the most desired with $45 \%$ to $77 \%$ water consumption reduction on the condition of similar washing quality. Soon, fully automated new washing machines were introduced in the market (Fig.5(b)).

\section{Wastewater Recycling (WWR)}

To promote WWR, TMG drafted "Guideline for Miscellaneous Use of Water" (Saito, 2003 ) in 1984. In the same year effective from April, TMG introduced a regulation 
making WWR practice mandatory for large-scale buildings with floor areas bigger than $30,000 \mathrm{~m}^{2}$ or buildings with potential non-potable water demand of more than $100 \mathrm{~m}^{3}$ per day (Chung and Meredith, 2008). In 2003, the Guideline for Promotion of Effective Utilization of Water was formulated. The baseline had been upgraded for buildings with floor areas bigger than $10,000 \mathrm{~m}^{2}$ or the development areas bigger than $30,000 \mathrm{~m}^{2}$ (Bureau of Urban Development, Tokyo Metropolitan Government, 2003). In addition, the Japanese Ministry of Construction granted subsidies of up to $50 \%$ of the capital costs for WWR construction to offset the associated costs and the government further assisted in connecting commercial WWR systems to the public sewerage system (Chung and Meredith, 2008). Continuous efforts by TMG in promoting WWR obviously contribute significant reduction of water consumption amount.

\section{Rainwater Harvesting (RWH)}

In Tokyo, there are ongoing large and small-scale RWH project practices which are initiated in order to encourage natural water cycle and to provide more stable water supply system. Sumida-ku is an example of a district where RWH is implemented actively also utilizing low-cost and transferable technology especially to make the most of its various benefits. Sumida-ku is also renowned as Amamizu (rainwater) City in Tokyo. Even though RWH is embraced in 'Tokyo Master Plan for Water Cycle' established in 1999, the utilization is mainly limited to Sumida-ku so far. According to officers in Sumida City Hall, there are 750 facilities with RWH both in private and public buildings to date.

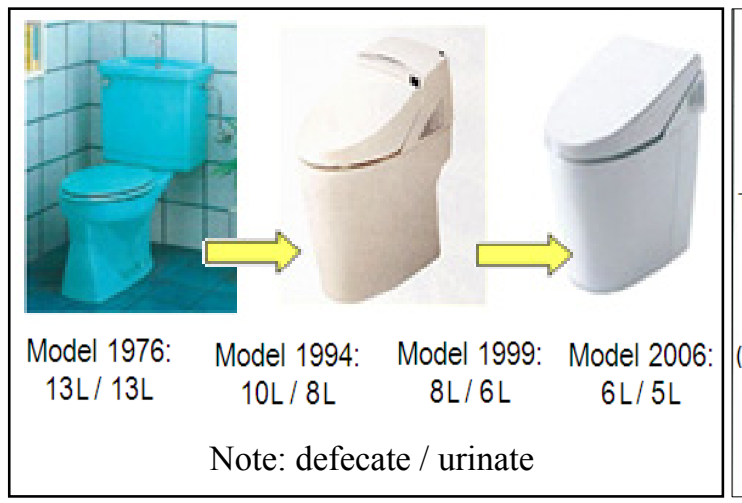

Fig. 5(a) - Flushing toilet development

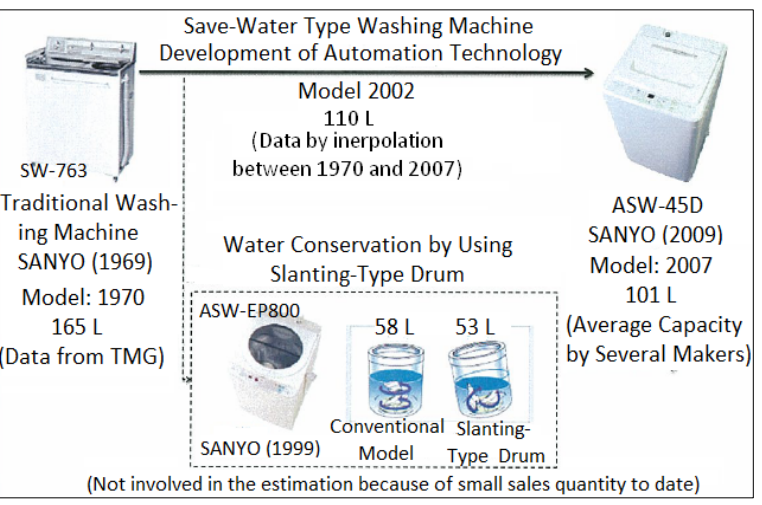

Fig. 5(b) - Washing machine development
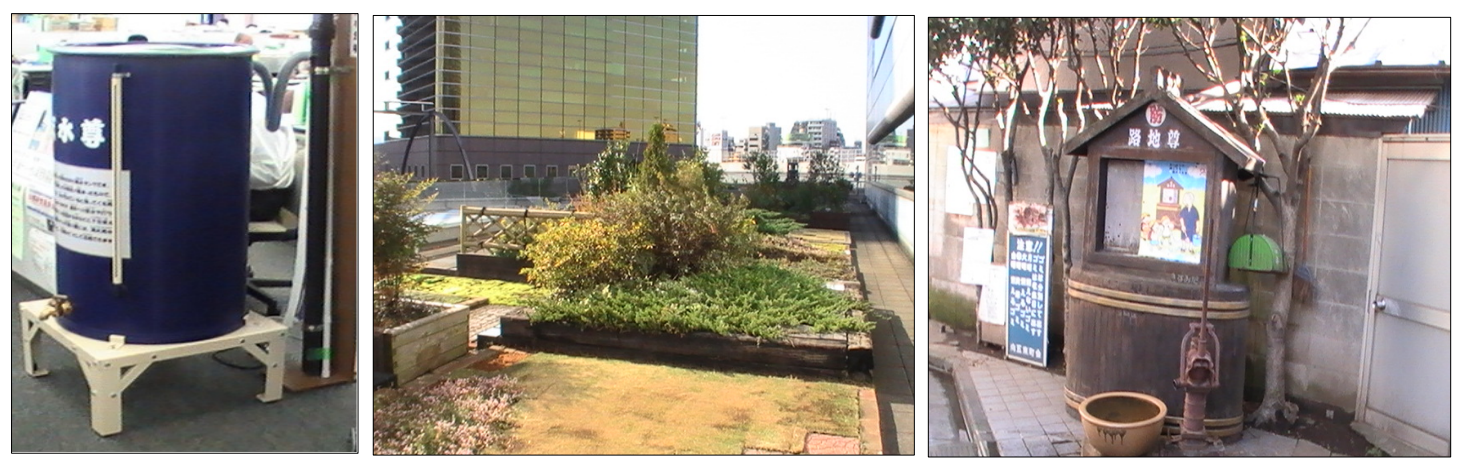

Fig. 6 - Rainwater utilization in Sumida-ku.

From left: small-scale RWH tank; large-scale RWH (rooftop of Sumida-ku Ward

Office as catchment area) and communal RWH called 'rojison' 
From the interviews with Sumida-ku officers, the authors of this paper were informed that the key elements in RWH implementation in this district are the mandatory system coupled with subsidy scheme, registration system and strong community involvement. The users receive subsidies which differ by the tank size if they register their RWH installation. Such registration system enables better management of RWH for future development. Moreover, starting from 2003 onwards, the mandatory requirement for RWH installation is imposed for the development of new buildings with floor areas of more than $10,000 \mathrm{~m}^{2}$. This mandatory system led to the increasing number of RWH installation and utilization in Tokyo.

\section{Reduction in Industrial Sector}

Reduction in factories mainly resulted in industrial water reduction. One of the major factors that contributed to such reduction was the relocation of large-scale factories in Tokyo such as Toyosu Gas, Ebisu Brewery, Kirin Beer and others to the outskirts of Tokyo. Another major factor was the reduction of water use in the factory through the utilization of WWR and water conservation efforts mainly due to their cost consciousness after the introduction of cumulative charging scheme in 1975.

\section{Water Conservation Effects by Indirect Demand Side Control $(\Delta Q 4)$}

Indirect demand side control measures consist of water consumption reduction by promoting mindset-change and behavior-change. The support by TMG through various measures serve two purposes toward water conservation; the first one is raising citizens' awareness for water conservation by public relation and the second one is triggering citizens' behavioral change by the introduction of cumulative charging system. For raising citizens' awareness for water conservation, it began in 1973 where TMG started the promotion of save-water activities. Special meeting was arranged in order to discuss the WCP. The committee concluded that the basis of the promotion was to raise self-awareness to custom over the habit of water users and to stimulate the public mind where the most appropriate approach was by making the public conscious about the difficulty in new water resources development. Among the actual activities conducted was the publication of save-water booklet for elementary schools in 1973 and for junior high schools in 1975. Also in 1975, water consumption monitoring activity started where the water usage of 700 households was monitored for a period of time to review the consumption pattern. However, according to TMG, the amount of reduction is not clear yet but they believe the awareness campaign has significantly contributed to water conservation.

Other than that, the Bureau of Waterworks in TMG carries out detailed PR activities by presenting daily-life water conservation methods through their homepage, videos, and pamphlets together with consultations through telephone calls for water conservation. They also continuously make efforts to promote the utilization of SWT devices including the distribution of free SWT-tap developed by them as shown in Fig.7. On the other hand, for triggering citizens' behavioral change, cumulative charging system was introduced. It took up to seven years to execute such cumulative charging system since there were controversial issues between political parties during the time regarding the charging system. The debate for the adequacy of such system was between the capitalist party and socialist party. The capitalist party opposed it, since the system is against the basic principles of capitalism which promote free market where per unit price will 

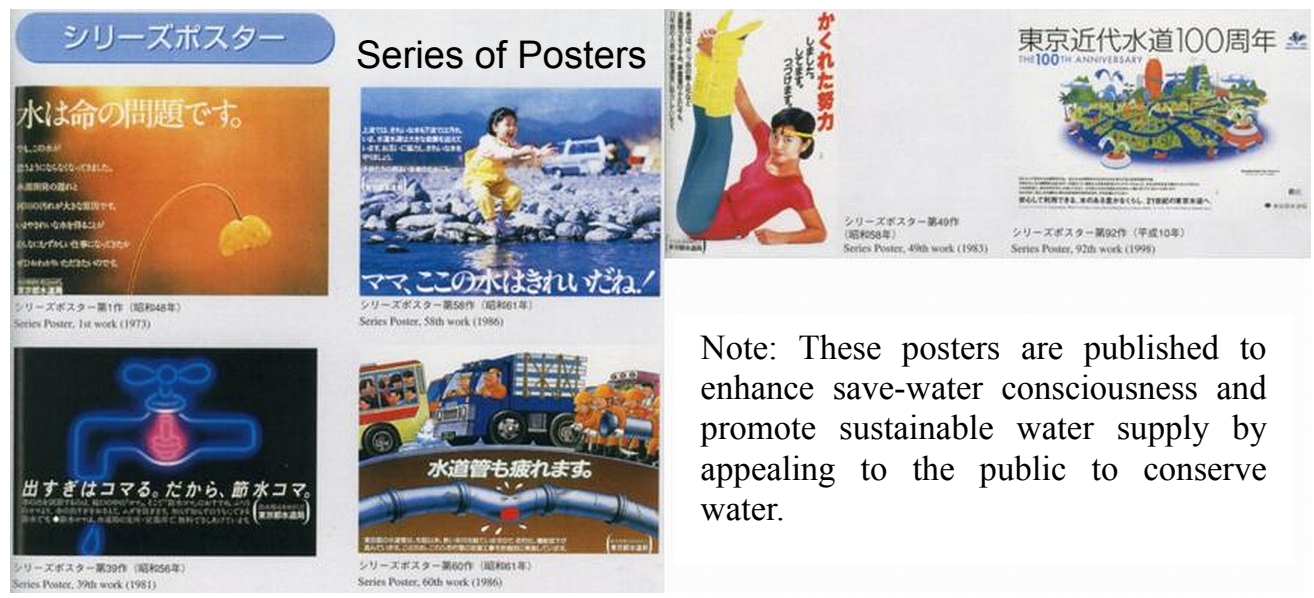

Note: These posters are published to enhance save-water consciousness and promote sustainable water supply by appealing to the public to conserve water.

Fig. 7 - Promotion activities for water conservation by TMG (Bureau of Waterworks, Tokyo Metropolitan Government, 1998)

become cheaper if the consumptions get bigger. On the other hand, the socialist party supported it, since it gives fair treatment among big consumers and small consumers. However, such system was successfully introduced in 1968 and was further intensified in 1975 where the cumulative increment structure became steeper and the bigger consumers had to bear expensive costs from the beginning. For $\Delta \mathrm{Q} 4$, it is difficult to estimate the amount saved by this intangible measure, hence reverse calculation was performed.

\section{Total Analysis on the Effects of Pushing-up and pulling-down Factors $(\Delta Q)$}

Based on the data from TMG as shown in previously mentioned Fig. 3, the amount of water consumption reduction in 30 years is $81 \mathrm{~L} / \mathrm{p} / \mathrm{d}$. From the above analysis, this amount is accounted by both pushing-up and pulling-down factors as discussed. Therefore, $\Delta \mathrm{Q}$ which is $81 \mathrm{~L} / \mathrm{p} / \mathrm{d}$ is represented by the following equation:

$\Delta \mathbf{Q}=$ (pulling-down factors $)-($ pushing-up factors $)$

$$
\begin{aligned}
& =(\Delta \mathrm{Q} 2+\Delta \mathrm{Q} 3+\Delta \mathrm{Q} 4)-(\Delta \mathrm{Q} 1) \\
& =(75+63.3+\Delta \mathrm{Q} 4)-(89.5) \\
& =48.8+\Delta \mathrm{Q} 4=81 \mathrm{~L} / \mathrm{p} / \mathrm{d} \ldots \ldots \ldots
\end{aligned}
$$

Likely, based on reverse calculation, indirect demand side control measure $(\Delta \mathrm{Q} 4)$ was calculated as follows:

$\Delta \mathrm{Q}=48.8+\Delta \mathrm{Q} 4=81 \mathrm{~L} / \mathrm{p} / \mathrm{d}$

Therefore, $\Delta \mathbf{Q} 4=81-48.8=32.2 \mathrm{~L} / \mathrm{p} / \mathrm{d}$

\section{Summary of the Analysis on the Effects of Pushing-up and Pulling-down Factors}

Tokyo managed to reduce $81 \mathrm{~L} / \mathrm{p} / \mathrm{d}$ of water consumption in 30 years by various measures from supply/demand side control introduced under WCP announced by TMG in 1973. Each element has a significant impact that contributes to the total per capita water consumption reduction. The weightage for each category under WCP is 44:56 for $\Delta \mathrm{Q} 2: \Delta \mathrm{Q} 3+\Delta \mathrm{Q} 4$. It indicates that the supply side control measures have relatively smaller impacts compared to demand side measures. Total demand side measures $(\Delta \mathrm{Q} 3$ $+\Delta \mathrm{Q} 4)$ are almost equal to supply side measures. Therefore, both supply/demand side measures are important to be considered in TWRM. In total, the actual conservation 
amount in Tokyo could be $171 \mathrm{~L} / \mathrm{p} / \mathrm{d}$ or more. However, due to pushing-up factors $(89.5$ $\mathrm{L} / \mathrm{p} / \mathrm{d}$ ) the actual reduction is equivalent to $81 \mathrm{~L} / \mathrm{p} / \mathrm{d}$ as mentioned.

\section{DISCUSSIONS}

\section{Programming of WCP in Tokyo}

Table 5 depicts the programming of WCP in Tokyo by highlighting the resisting and driving factors relevant to each measure. Accordingly, each measure under Tokyo's WCP is categorized by strategic approaches into several dividing lines corresponding to the applicability level. Thus, for supply side control measures, the applicability is dependent on the sole decision by the water supply body (TMG) through cost and benefit analysis. In case of demand side control measures, the dividing line is basically in accordance with socio-economic conditions ranging from voluntary scheme to mandatory scheme.

Table 5 - Classification of elements in 'Water Conservation Plan' from strategic approach based on resisting and driving factors

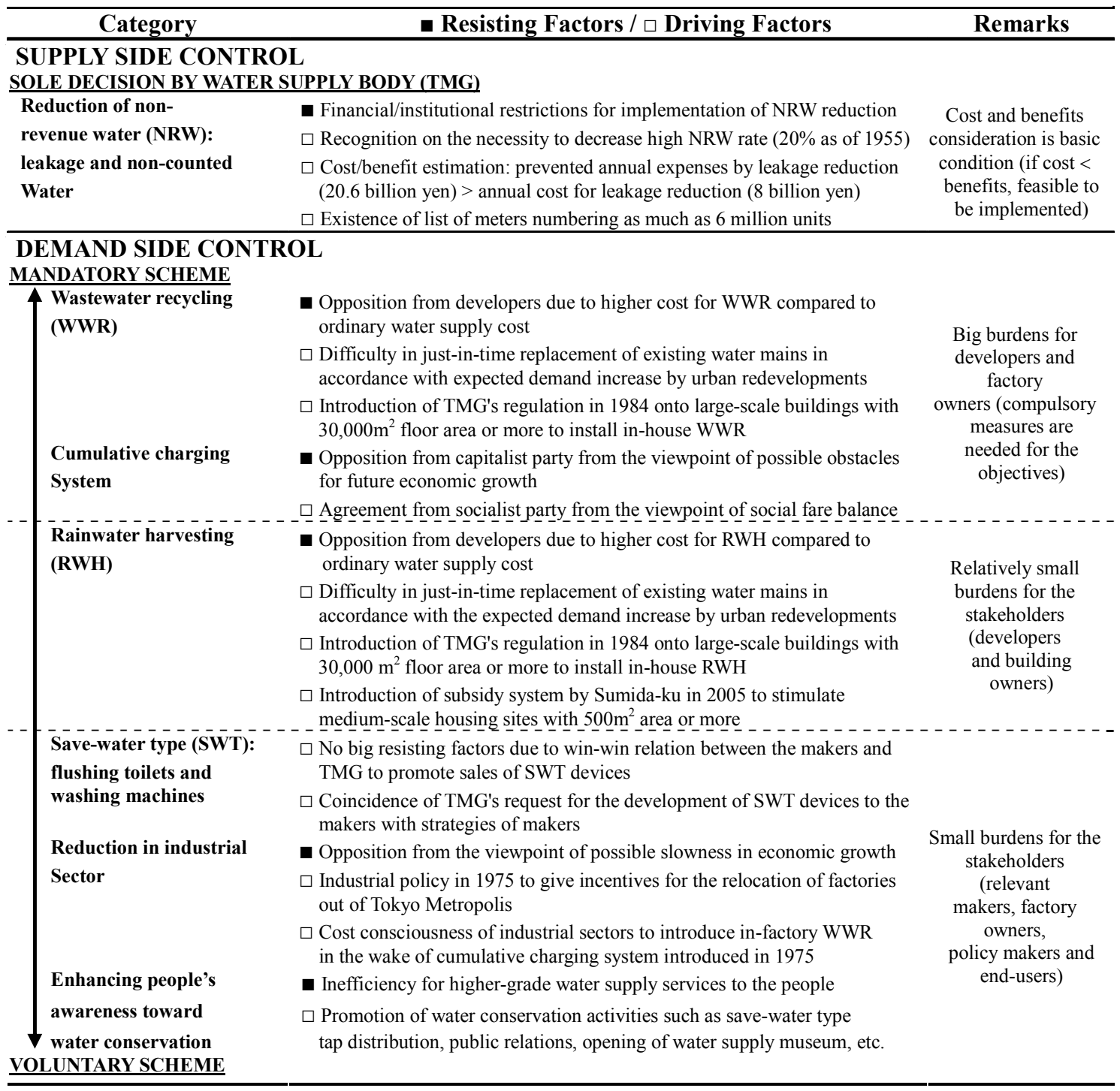




\section{Mandatory Scheme}

The introduction of WWR and cumulative charging system are considered as mandatory schemes, since compulsory programmes are needed for the objectives such as the introduction of regulation and strong governance to raise water tariff. The resisting factors for mandatory scheme are more difficult to overcome and they usually take longer periods to be realized. For instance, it took up to 7 years to reach agreements between the socialist and capitalist party to introduce the cumulative charging system.

\section{Intermediary Scheme}

Rainwater harvesting is considered as intermediary scheme in Tokyo's WCP, since the stakeholders (comprised of the developers and building-owners) tend to volunteers for RWH installation to realize water conservation. The practice of RWH is relatively acceptable for Japanese people because they have a tradition of valuing natural resources. The clear example of such practice is the cascade use of water for cleaning rice and the washings would later be used for watering plants to utilize the remaining nutrients. Likewise, making the most of rainwater by RWH should be the priority.

However, since the installation and running cost of RWH are rather high than the ordinary water supply, the support by subsidy system, such as the one practiced in Sumida-ku would be appropriate. Furthermore, the availability of low-cost technology compared to WWR agitates RWH utilization. Therefore, the resisting factors in this intermediary scheme pose relatively small burdens especially when compared to measures under mandatory scheme. Realization of water conservation by this measure would be more successful, if the driving factors could be enhanced by intensifying the regulation, promotion and subsidies.

\section{Voluntary Scheme}

The introduction of SWT devices, water demand reduction in the industrial sectors and enhancement of people's awareness are considered as voluntary scheme, since they should offer a win-win relation among stakeholders including the makers, the factory owners and citizens, as well as the water supply body to realize water conservation. Furthermore, resisting factors in voluntary scheme are comparatively smaller due to some reasons for instance, the development of SWT devices corresponds to TMG's enthusiasm to reduce water consumption. In the industrial sectors, water consumption reduction is rather easily materialized, as it helps to save water cost for the factory owners. In case of people's awareness enhancement, Japanese people traditionally have 'mottainai' mindset, which means a sense of regret concerning waste of resources. Thus, TMG's public relation activities easily ignite their voluntary spirit for water conservation. Whereas, the driving factors for voluntary scheme normally provides benefits for the relevant stakeholders resulting in the ease of realization.

\section{Summary}

In general, in terms of the applicability of WCP, the first priority should be the supply side control measure which is the reduction of NRW, if cost-benefit analysis proves practicality. It is relatively easy to push through, since the sole decision by the water supply body is the basis. Subsequently, the voluntary scheme is easier to be executed since the resisting factors usually have simple solutions, whereas, the driving factors provide benefits usually leading to win-win relation for all the stakeholders. Following 
the voluntary scheme, the intermediary scheme is assumed to be not so burdensome.

For the applicability of the mandatory scheme programming comprising WWR and cumulative charging system, Tokyo successfully managed to overcome the resisting factors in the basis of strong governance of TMG. In addition, the Japanese mindset, where normally the people will abide by regulations once realized, is helpful to boost this scheme. Such Japanese tendencies seem to be rare in other countries, where people oppose to their endurance imposed by bigger burdens such as investment on WWR or increment of water tariff. In case of the application of Tokyo's WCP to developing countries, the following should be fully investigated: the balance between resisting/driving factors, the government's willingness to overcome the difficulties particularly for mandatory scheme, and the people's willingness to be involved in water conservation programming.

\section{CONCLUSIONS}

In this study, the following were clarified:

1. This study provides a good tool for TWRM in the basis of Tokyo's experience known as 'Water Conservation Plan' which can serve as efficient water-use programmes especially for developing countries facing rapid urbanization and population growth.

2. Tokyo faced tight water resources problem during high economic growth period. However, by incorporating both supply/demand side control under WCP, Tokyo became advanced in water resources management and at present, Tokyo has excess water supply to meet the demands.

3. Tokyo managed to reduce per capita water consumption to about $171 \mathrm{~L} / \mathrm{p} / \mathrm{d}$ or more but due to pushing-up factors, which contributed $89.5 \mathrm{~L} / \mathrm{p} / \mathrm{d}$ of increment, the actual reduction was equivalent to $81 \mathrm{~L} / \mathrm{p} / \mathrm{d}$ in 30 years or $19 \%$ from the total water supply.

4. This study also provides quantitative analysis together with the programming for each measure under WCP as a reference for other regions facing similar problems.

5. For the applicability of WCP, considering the resisting/driving factors from Tokyo's experience, the first priority is NRW reduction from supply side control followed by voluntary scheme i.e. SWT devices development, water demand reduction in industrial sectors and enhancement of people's awareness towards water conservation. The implementation of intermediary scheme i.e. RWH and finally the execution of mandatory scheme i.e. WWR and cumulative charging system must be subsequently carried out.

6. However, the applicability of WCP in Tokyo especially the mandatory scheme is highly related to Japanese mindset where the Japanese people traditionally pose 'mottainai' mindset firmly and abide by the established government rules and regulations.

7. The applicability of the measures implemented in Tokyo is worth evaluated for other developing countries considering local socio-economic conditions to encourage water conservation and sustainable TWRM.

\section{REFERENCES}

Abderrahman W. A. (2000). Water Demand Management and Islamic Water Management Principles: A Case Study, International Journal of Water Resources Development, 16(4), 465-473. 
Bureau of Urban Development, Tokyo Metropolitan Government (2003). Guidelines for Promotion of Effective Water Resources Utilization, Tokyo Metropolitan Government, Tokyo, Japan. (in Japanese)

Bureau of Waterworks, Tokyo Metropolitan Government (1973). Experimentation Report of Reasonable Water Use of Washing Machines, Tokyo Metropolitan Government, Tokyo, Japan. (in Japanese)

Bureau of Waterworks, Tokyo Metropolitan Government (1979). Annual Report on Water Supply, Tokyo Metropolitan Government, Tokyo, Japan.

Bureau of Waterworks, Tokyo Metropolitan Government (1998). Centennial Water Supply Record, Tokyo Metropolitan Government, Tokyo, Japan.

Bureau of Waterworks, Tokyo Metropolitan Government (2007). Annual Report on Water Supply, Tokyo Metropolitan Government, Tokyo, Japan.

Bureau of Waterworks, Tokyo Metropolitan Government (2009). Water Supply in Tokyo: Provision of Excellent Water and High-Quality Service, Tokyo Metropolitan Government, Tokyo, Japan.

Chung K. and Meredith P. W. (2008). Greywater Reuse: Understanding Greywater Reuse Systems in the Current and Future Contexts and How Individuals Can Promote Greywater Reuse, CRP 3840: Green Cities.

DeCook K. J., Foster K. E. and Karpiscak M. M. (1988). The W-Index for Residential Water Conservation, Water Resources Bulletin, 24(6), 1295-1301.

Fenwick K. (1998). Conservation Begins at Home, Resource, 6(8), 18-19.

Fujii T. (2002). Evaluation on Save Water Policy Package in Fukuoka-Shi, Journal of Japan Water Supply Systems, 71(7), 3-13. (in Japanese)

Japan Electric Appliances Association (2009). Household Appliances Statistics, Japan Electric Appliances Association, Tokyo, Japan.

Japan Water Works Association (JWWA) (1997). Seismic Design and Construction Guidelines for Water Supply Facilities, JWWA, Tokyo, Japan.

Karpiscak M. M., Brittain R. G., and Foster K. E. (1994). Desert House: A Demonstration/Experiment in Efficient Domestic Water and Energy Use, Water Resources Bulletin, 30(2), 329-334.

Masuda S. (2009). Japan's Official Development Assistance (ODA) in the Water Sector, Journal of Japan Society on Water Environment, 32(8), 397-400.

Mayer P. W., DeOreo W. B., Opitz E. M., Kiefer J. C., Davis W. Y., Dziegielewski B. and Nelson J. O. (1999). Report on Residential End Uses of Water: Denver, Colorado. American Waterworks Association Research Foundation.

Ministry of Land, Infrastructure, Transport and Tourism (MLIT) (2003). Transition of the amount of water usage for life, http://www.mlit.go.jp/tochimizushigen/mizsei/ c_actual/images/03-03.gif (August 21, 2010). (in Japanese)

Murase M., Nakamura A., and Kawasaki H. (2005). An analysis for demand structure and price of domestic water supply. Proceedings of Hydraulics Engineering, JSCE. 49, 475-480. (in Japanese)

Nakagawa N., Kawamura A. and Amaguchi H. (2010). Analysis of Decreasing Tendency of Domestic Water Use per Capita in Tokyo. BALWOIS 2010 - Ohrid. Republic of Macedonia.

Saito N. (2003). Promotion of Public Awareness of Water Conservation in Tokyo, Japan. Purification Division, Tokyo Metropolitan Waterworks Bureau.

Statistics Bureau, Ministry of Internal Affairs and Communication (1980). Population Census. Japan Statistical Yearbook 1980, Statistics Bureau, Ministry of Internal 
Affairs and Communications, Tokyo, Japan.

Statistics Bureau, Ministry of Internal Affairs and Communication (1994). National Census, Statistics Bureau, Ministry of Internal Affairs and Communications, Tokyo, Japan.

Statistics Bureau, Ministry of Internal Affairs and Communication (2005). Population Census. Japan Statistical Yearbook 2005, Statistics Bureau, Ministry of Internal Affairs and Communications, Tokyo, Japan.

Statistics Bureau, Ministry of Internal Affairs and Communication (2007). National Census, Statistics Bureau, Ministry of Internal Affairs and Communications, Tokyo, Japan.

White S. B. and Fane S. A. (2002). Designing Cost Effective Water Demand Management Programs in Australia, Water Sci. and Tech, 46 (6/7), 225-232.

White S. (2000). Water Demand Management and Conservation Including Water Losses Control - National Report Australia, Water Supply, 18(1-2), 180-181.

Yamada K., Tanaka K., Sato Y. and Higashi Y. (2004). The structure analysis of domestic water demands according to the size of the households. Proceedings of Environmental System, JSCE. 32, 403-406. (in Japanese) 